\title{
La realidad globalizada en la pintura figurativa contemporánea. El archivo virtual como estrategia.
}

\section{Globalized reality in contemporary figurative painting. The virtual file as strategy.}

\author{
TIPO DE TRABAJO: \\ Comunicación \\ PALABRAS CLAVE: \\ Globalización, arte, pintura, proceso. \\ KEY WORDS: \\ Globalization, art, painting, process.
}

RESUMEN.

La sociedad contemporánea globalizada influye en la pintura actual, sea cual sea su localización, que se nutre del flujo constante de información, de la tecnología cambiante y de las imágenes que consumimos a través de diferentes medios.

La realidad del artista, como inevitablemente la de todos los individuos, está compuesta por las experiencias físicas y las vividas en la RED internet. Las primeras nos hablan del entorno próximo y cotidiano del artista, son las imágenes de la realidad natural que incorpora en la obra. Las segundas pertenecen a una realidad lejana y desconocida. Es una ventana al mundo, una apropiación del colectivo social del cual formamos parte. Ambas realidades conforman una nueva figuración pictórica, como también una nueva identidad entre lo real y lo virtual y lo local y lo global.

Numerosos artistas trabajan con un banco de imágenes catalogadas y revisadas constantemente que proceden de internet. Detectamos diferentes estrategias del trabajo de archivo: desde la búsqueda precisa de Andrea Canepa que rastrea a partir de un guión previo; pasando por las asociaciones que realiza Javier Martín, a partir de una palabra surgen una serie de imágenes; hasta los tanteos intuitivos de José Carlos Naranjo quién se deja llevar por las impresiones y sensaciones.

Con esta propuesta pretendemos conocer algunas estrategias contemporáneas que originan un diálogo entre la realidad individual y la colectiva. Una globalización basada en la hibridación, la transitoriedad, el simulacro y la inmediatez. En definitiva, un nuevo espacio que condensa las diversas realidades del artista.

\section{ABSTRACT.}

Contemporary globalized society influences present painting, regardless of its location, which thrives on the constant flow of information, on the changing technology and on the images we consume through different media. 
The artist's own reality, as inevitably of all individuals, is composed by physical and vivid experiences on the Internet. The first that tell us about the artist's nearby and daily environment are the images of natural reality, which he incorporates in the artwork. The latter belong to a distant and unknown reality. It is a window to the world, an appropriation of the social community which we are part of. Both realities form a new painting, as also a new identity between the real and virtual and the local and global.

Many artists work with an indexed and constantly reviewed image database coming from the Internet. We detect different strategies in file working: from Andrea Canepa's accurate search who traces from a previous script; through the associations made by Javier Martin, from a single word comes up a series of images; to José Carlos Naranjo's intuitive tries who's carried away by impressions and sensations.

With this proposal we intend to find out some contemporary strategies that originate a dialogue between the collective and individual reality. A globalization based on hybridization, transience, the drill and the immediacy. Ultimately, a new space that condenses the artist's various realities.

\section{CONTENIDO.}

\section{INTRODUCCIÓN.}

De la misma manera que la invención y difusión de la fotografía influyó en la pintura de su tiempo ocurre con los nuevos soportes virtuales en el arte más reciente. Portadores de imágenes incesantes que consumimos a diario sin apenas darnos cuenta. Muchos pintores son conscientes de este hecho y lo incorporan en su obra con diversas intenciones: estéticas, procedimentales y conceptuales. Pero sin duda, la gran particularidad de estas imágenes radica en su desconocida procedencia territorial y de autoría, conformando un repertorio colectivo en la red internet.

Entre los numerosos artistas interesados en este medio virtual hemos seleccionado -pues representan tres formas diferentes de investigación- a: Andrea Canepa (Lima, 1980), Javier Martín (EI Viso del Alcor, 1979) y José Carlos Naranjo (Villamartín, 1983). Como veremos, desde diferentes posicionamientos nuestros protagonistas desarrollarán sus obras pictóricas utilizando como recurso procedimental internet. En este encuentran una infinidad de posibilidades plásticas y de información, ya que pueden acceder a lugares y realidades privadas desconocidas para ellos.

Con este estudio pretendemos mostrar cómo los avances informáticos de comunicación -la cibercultura- influyen en la identidad del individuo, y por tanto, en el arte más actual donde existe un diálogo entre imágenes de la realidad cercana e íntima del artista y otras obtenidas a través de la realidad virtual.

\section{LA IDENTIDAD CONTEMPORÁNEA GLOBALIZADA.}

La época actual globalizada está caracterizada por una constante inestabilidad y dinamismo. Todo lo visual está en continuo cambio, lleno de interconexiones que debilitan la singularidad de la imagen. De la misma manera ocurre en el ser humano, no existen identidades puras, marcadas por la pertenencia a un espacio sino identidades, como denomina Bourriaud "radicantes" ${ }^{1}$. Se refiere a la capacidad inmediata y constante de adaptación del individuo. No es una opción, sino una obligación, si se quiere formar parte del colectivo:

"La tarea de las nuevas generaciones es aprender a vivir no sólo en el amplio mundo de una tecnología cambiante y de un flujo constante de información, sino ser capaces al mismo tiempo de mantener y refrescar también nuestras identidades locales. El desafío es poder desarrollar un concepto de nosotros mismos como ciudadanos del mundo y, simultáneamente, conservar nuestra identidad local como mexicanos, zapotecos, españoles o catalanes. Posiblemente tal desafío representa [...] una carga como nunca en la historia". 2

Por tanto, la identidad artística se basa en la hibridación entre los valores culturales del contexto del artista y el del arte contemporáneo global. Es un ejercicio de traducción, donde el artista interpreta de un modo singular multitud de unidades culturales. Pues, según Bourriaud el arte:

\footnotetext{
${ }^{1}$ BOURRIAUD, Nicolás. Radicante. Buenos Aires: Adriana Hidalgo, 2009. p22.

2 BOLÍVAR, Antonio. "Globalización e identidades: (des)territorialización de la cultura". Revista de Educación, núm. Extraordinario, Universidad de Granada, 2001. p283.
} 
“...tiene que dejar de clasificar la obra según las pertenencias culturales y territoriales. En un mundo en proceso acelerado de la globalización, donde el concepto del espacio cultural se repiensa continuamente por el desarrollo veloz de los medios de comunicación, es impensable localizar al artista y su obra en un punto espacial específico". ${ }^{3}$

El hecho de que numerosos artistas se nutran de internet conlleva implícito un "riesgo", la globalización de la imagen, no se diferencia del artista que vive en otra parte del mundo. El resultado pictórico comparte características comunes con otros artes de otros territorios. $Y$ es que el arte contemporáneo nace con unas expectativas muy amplias, pues quiere ser observado y analizado por un consumidor universal. Esto plantea un problema en la esencia de la creación, la difícil libertad del artista. A saber:

“...la globalización del mercado del arte parece que, en primera instancia, disminuye la libertad para expresar la subjetividad y los principios del artista, al ver éste su creatividad supeditada a la comercialización. Tanto el espectador como el coleccionista o "consumidor de arte" ejercen hoy un papel que crea cierta controversia, pues el artista actual, ante el mercado globalizado, depende del cliente, y si no responde a la demanda del mercado corre el riesgo de quedar relegado. De este modo, la libertad creativa se enfrenta al peligro de verse mermada, incluso anulada,...". ${ }^{4}$

Sea como fuere, el resultado artístico de nuestra época posee unas características que lo definen: la artificialidad como vía de conocimiento y la transitoriedad de la imagen que muta constantemente o desaparece y que eleva, como nunca, el nivel de subjetividad de las apariencias. De hecho, nuestros protagonistas pertenecen a una generación donde coincide la madurez artística con el auge de las redes sociales y la imagen virtual. Ellos son conscientes de la importancia y presencia de estos soportes en la creación, como todo verdadero arte hijo de su tiempo.

\section{ALGUNAS ESTRATEGIAS PICTÓRICAS RECIENTES.}

Desde el Atlas Mnemosyne de Aby Warburg, obra de archivo creada a partir de imágenes yuxtapuestas reproducidas -grabados, recortes de prensa, mapas, postales- o fotográficas, pues era su fin, no han cesado los artistas que lo practican ${ }^{5}$. Sin embargo, para nuestro estudio la imagen se convierte en parte del proceso, es decir, es un recurso que necesita el pintor para crear. De la misma manera que otros artistas utilizan el natural para representar la realidad. Por este motivo surge el archivo o banco de imágenes ${ }^{6}$. Además, la imagen ya no es analógica, sino digital. Este hecho facilita enormemente la labor del pintor ya que puede manipularla a su antojo antes de ser llevada al soporte pictórico.

Tras el archivo encontramos un trabajo de investigación concienzudo y prolongado en el tiempo, donde el artista cataloga en carpetas las imágenes que encuentra en internet. Como veremos, cada uno de nuestros protagonistas aborda el archivo de un modo diferente, son tres búsquedas en la red.

La obra de Andrea Canepa gira en torno a los factores de tiempo y espacio, pues realiza auténticos viajes cibernéticos programados. Un ejemplo de ello lo encontramos en el proyecto Todas las calles del año de 2012-2015 (il.1). Esta investigación se apoya en aplicaciones digitales de mapas como Google Street View para recopilar imágenes de lugares asociadas a los 365 días del año. Comenzando con el 1 de enero de 1959 que representa el triunfo de la revolución cubana. La ubicación geográfica de su búsqueda se concreta en Latinoamérica. En definitiva, nos habla de la memoria histórica y, de un modo más esencial, de la identidad de los pueblos.

\footnotetext{
${ }^{3}$ BORISOVA, Anna. "Arte e identidad en la época de la globalización". Arte y políticas de identidad. Vol 6. Universidad de Murcia, 2012. p275.

${ }^{4}$ SALANOVA, Marisol y CABANES, Eurícide. "Arte versus Globalización: Revisión Filosófica de los recursos del Arte Contemporáneo frente al proceso de Globalización”. Eikasia. Revista de Filosofía, [en línea]. Año V, 31. 2010. [fecha de consulta: 6 Marzo 2017]. Disponible en: http://www.revistadefilosofia.com

${ }^{5}$ No obstante, la utilización de la imagen reproducida en la creación pictórica ha existido desde los ismos. En los collages cubistas de Picasso y dadaístas de Hannah Höch y Raoul Hausmann.

${ }^{6}$ Francis Bacon es uno de los grandes exponentes del trabajo de archivo en la creación pictórica. En su estudio se podían encontrar montañas de fotografías, recortes de prensa y periódicos de sucesos, siendo la violencia el común denominador de las imágenes. Se podría decir que su búsqueda estaba basada en una idea.
} 

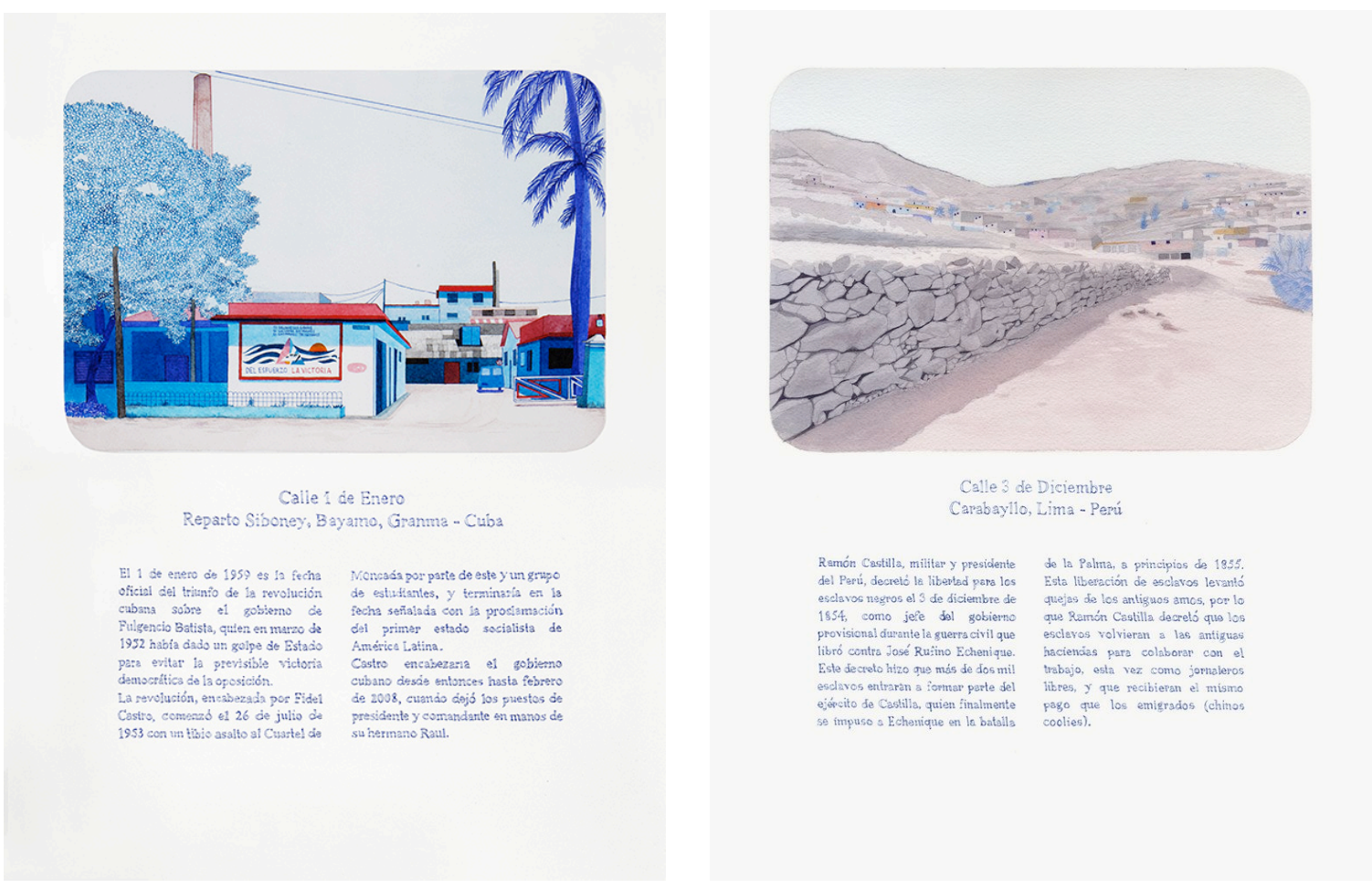

llustración 1. A. Canepa. Todas las calles del año, 2012-2015. Técnica mixta sobre papel. $31 \mathrm{~cm}$ x $41 \mathrm{~cm}$.

Canepa aborda cada trabajo con un guión muy organizado, con gran rigor en la clasificación de las imágenes que encuentra en internet, sabiendo con precisión qué idea busca. Aunque, lógicamente, en el proceso intervienen factores intuitivos y emocionales. Pero la artista no se queda ahí, necesita codificar cada una de las imágenes mediante el dibujo -representa sobre papel con rotuladores, tinta china o acuarelas- pues es el objetivo del proyecto. Cada dibujo describe un lugar diferente que gracias a la uniformidad del formato y el procedimiento consigue que haya unidad. De este modo, no plantea conflictos integradores como veremos en otros autores que relacionan varias imágenes en un mismo soporte.

Como toda búsqueda investigadora comienza con una palabra -ya sea en una enciclopedia o en cualquier buscador- que deriva en una imagen y bibliografía que le permiten conocer la historia de los lugares que representa. Procedimiento cognitivo apoyado en el trinomio pensamiento, lenguaje e imagen. Realmente, como la mayor parte del arte conceptual, la imagen y el texto son recursos habituales en su obra. En este caso, también se debe al hecho de que es un almanaque, y como tal, la imagen y el lenguaje se complementan.

Por otra parte, Canepa realiza también algunas creaciones plásticas que se alejan de la representación pictórica pero que continúa el discurso de una sociedad globalizada. Acciones como el envío de postales antiguas compradas por internet que muestran rincones de la ciudad de Granada y los datos del remitente y destinatario original -El lugar que corresponde de 2015-. La artista se desplaza a las coordenadas del destinatario y hace fotografías urbanas registrando los cambios que ha experimentado el lugar para convertirlas de nuevo en postales que enviará de vuelta a la ciudad de Granada ${ }^{7}$. A diferencia del proyecto pictórico anterior, los viajes son físicos tanto los de la artista como los de las postales. Otro tipo de recorridos posee la reciente instalación de Canepa IEC 60086 de 2017 . La artista conecta 11 clavijas eléctricas -las que existen en todo el mundo- a través de cables en cuyo extremo se enciende una luz. El discurso es claro: "...en su origen las infraestructuras eléctricas se desarrollaron de manera independiente en cada país, en un momento en el que la actual globalización quedaba lejos y resultaba difícil imaginar que los dispositivos eléctricos llegarían algún día a ser portátiles". 8

\footnotetext{
${ }^{7}$ En realidad son amigos de la artista que viven en diferentes ciudades españolas los que se encargan de enviar las nuevas postales. Acto similar al que hiciera On Kawara desde mediados de los 60 cuando enviaba postales con mensajes cortos a sus amigos.

${ }^{8}$ ESPINO, Luisa. Andrea Canepa. La verdad está en otra parte. Domus Artium 2002. [en línea]. 2017. [fecha de consulta: 8 Marzo 2017]. Disponible en: http://domusartium2002.com/es/EXPOSICION/andrea-canepa-2017
} 
Si Andrea Canepa realiza una búsqueda cibernética de manera programada, Javier Martín se embarca en una aventura azarosa, de asociaciones disparatadas del lenguaje y la imagen en su proyecto El Vicio del Alcohol ${ }^{9}$ de 2015 . Es decir, el artista "ha creado partiendo de cadenas y familias verbales, relacionando palabras por su cercanía bien fonética bien paronímica, homonímica, etc" ${ }^{10}$ Un juego de palabras que remiten inevitablemente al que practicara Raymond Roussel en su obra Impresiones en África y que tanto influyó en el discurso de Marcel Duchamp. Si Roussel buscaba una narración absurda y desconcertante, nuestro protagonista pretende ampliar las múltiples asociaciones interpretativas, romper el lenguaje para motivar la fantasía, la reflexión.

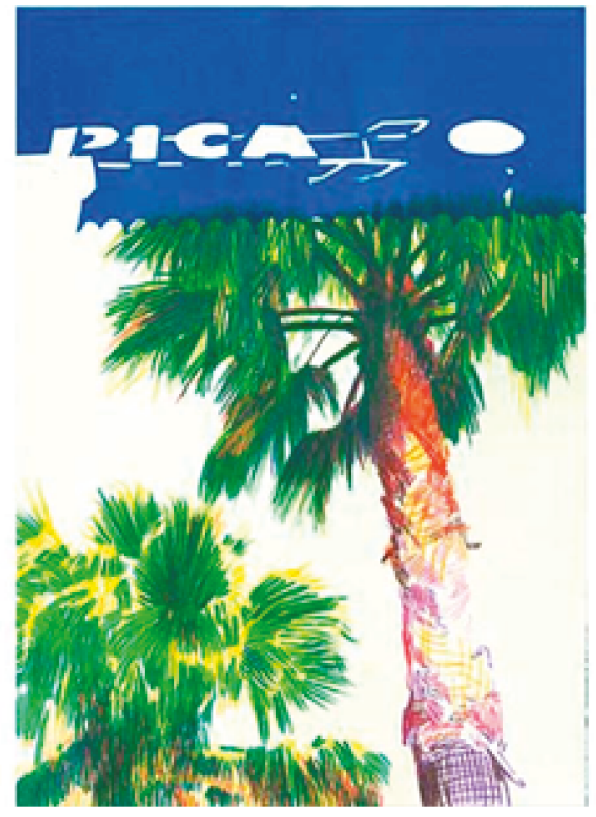

Ilustración 2. J. Martín. Cómo pinté algunos cuadros míos, 2015.

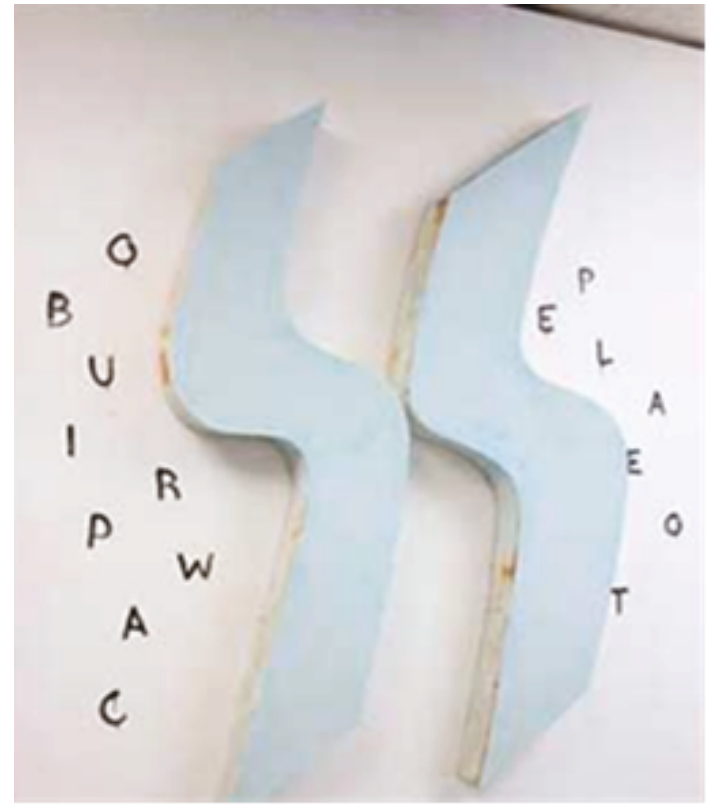

Ilustración 3. J. Martín. Hotel Picasso, 2015.

El proceso consiste en "...el equívoco referencial que en los buscadores de imágenes del navegador de internet se da asiduamente entre el término verbal de la búsqueda y el resultado de imágenes". ${ }^{11}$ Martín parte de una palabra que le lleva a una infinidad de imágenes que el buscador conecta con el término pero que a simple vista nada tienen que ver con él. Se produce una disociación entre la imagen y el concepto, una encadenación de malentendidos o equívocos lingüísticos e iconográficos ${ }^{12}$ como el que genera la palabra Picasso. La idea surge de la realidad cercana del artista. El rótulo de un hotel abandonado en su pueblo, el Hotel Picasso, que provoca una serie de obras interconectadas. La ausencia de las dos eses en el dibujo (il. 2) conecta con la escultura Hotel Picasso (il.3) que sirven de nexo de unión para la construcción de otras palabras: de Picasso a picao. En definitiva se trata de la desintegración del lenguaje y de la imagen. Esta última a través de la técnica puntillista que descompone la realidad visual. Puntillismo que ayuda a configurar la tipografía de la obra Misunderstanding (il.4) inspirada en la Boîte verte de Duchamp. Escribe malentendido en inglés jugando con la inversión de las letras y también con los recorridos perceptivos.

\footnotetext{
${ }^{9}$ Título que recibe la exposición basándose en el nombre de su localidad natal, El Viso del Alcor.

${ }^{10}$ LA CAJA CHINA [en línea]. Nota de prensa. Sevilla: Galería de Arte La Caja China, 2015- [fecha de consulta: 12 Marzo 2017]. Disponible en: http://www.lacajachina.net/images/exposiciones/javiermartin/notaprensa.pdf

${ }^{11}$ Op. cit.

${ }^{12}$ Estas asociaciones ambiguas y contradictorias fueron desarrolladas hace aproximadamente un siglo por Magritte en la obra Esto no es una pipa, perteneciente a la serie "la traición de las imágenes". Como apuntaba Michel Foucault en su libro Esto no es una pipa. Ensayo sobre Magritte hay una duplicidad en la lectura de las palabras: a veces se interpretan como lenguaje y otras como imágenes de palabras.
} 


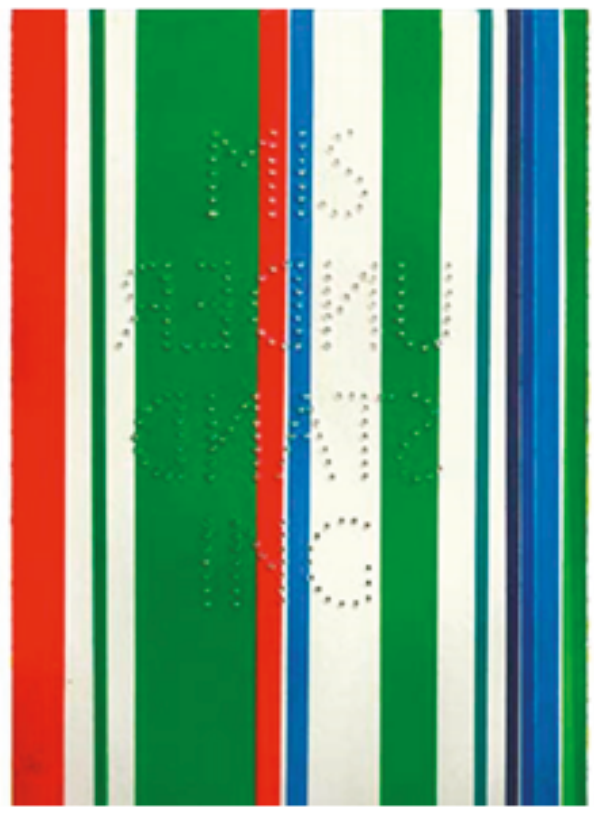

Ilustración 4. J. Martín. Misunderstanding, 2015.

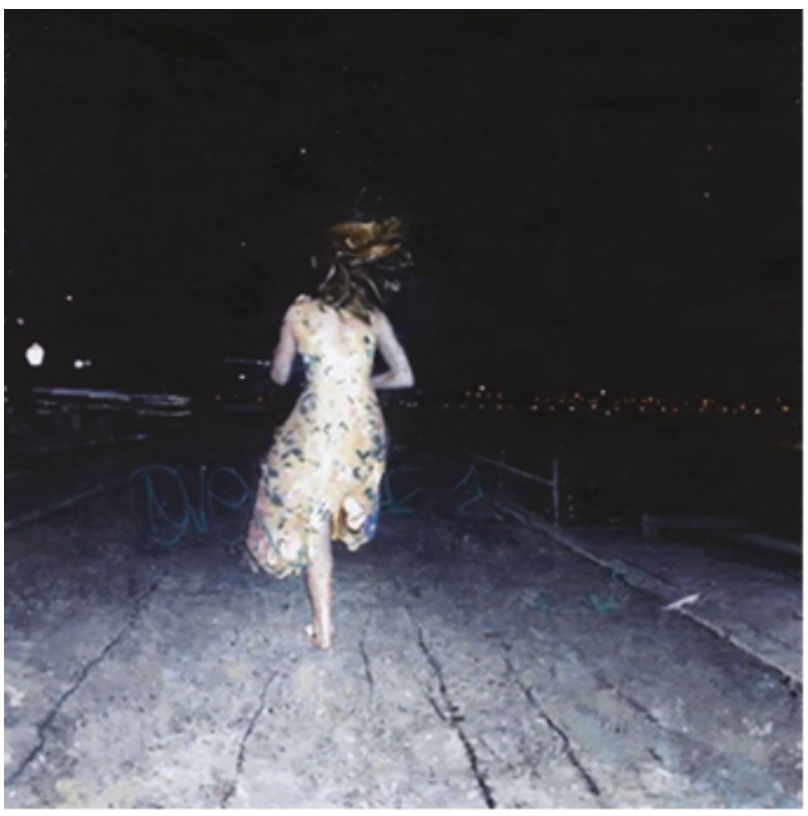

Ilustración 5. J. C. Naranjo. El camino, Óleo sobre lienzo, 2013.

El trabajo de Javier Martín no sería posible sin internet pues este soporte facilita la búsqueda de asociaciones entre texto e imagen. Su obra es el reflejo de una sociedad hiperconectada y globalizada, que se nutre de un repertorio de imágenes que vienen a objetivizar los conceptos que preocupan al artista: "Esas cadenas verbales con las que trabaja no hacen sino ampliar una serie de obsesiones y lugares comunes dentro de su trabajo que enriquecen la lectura de su pintura". ${ }^{13}$

Como hemos visto en su obra conviven la realidad próxima del artista -algunas ideas surgen de su entorno cercano, como la del Hotel Picasso- y la virtual, donde desarrolla la búsqueda de imágenes. Procedimiento similar al que experimenta José Carlos Naranjo. Sus pinturas son el resultado de una compilación de imágenes de diversas procedencias. Así lo afirma el artista:

"Yo siempre trabajo con un banco de imágenes e intento que sea lo más amplio posible y nutrirlo casi a diario. Hoy en día es muy fácil con una simple captura del móvil y lo ordeno en carpetas en el ordenador junto con fotografías que voy encontrando y las visualizo de vez en cuando, como el que ve una película y de algún modo están ahí en la memoria. Recuerdo que para El camino (il.5) la imagen de la chica corriendo era completamente diferente, estaba en un bosque, el suelo era césped y estaba desenfocada. Para otra obra anterior, me fui una noche a los aledaños de Sevilla e hice muchas fotos de caminos, de asfalto, de arena, con grietas, sin grietas,..., son fotos que no tienen calidad, ni me interesa, porque si no acabaría copiándolas. A veces parto de imágenes feas y malas e intento en el cuadro extraer lo que me interesa. Utilicé seis imágenes para El camino. El puente, el asfalto, la ciudad que había detrás, las luces, el cielo,...eran muy dispares pero luego quedó como una unidad". ${ }^{14}$

Las fotografías que realiza Naranjo de su entorno cercano dialogan con otras rescatadas de internet, revistas y enciclopedias. Una búsqueda azarosa e intuitiva que a medida que transcurren los años genera una estética personal, así el artista tiende a un tipo de imágenes. La intención es unificarlas en el cuadro, crear un nuevo espacio coherente y globalizado donde habitan sus protagonistas, es decir: "Recurre a caminos de tierra y asfalto que poseen una gran universalidad, podrían parecer espacios que el espectador conoce e identifica. De hecho, muchos observadores preguntan al artista si dichos lugares se corresponden con otros que ellos creen reconocer en las obras. Quizás esta cualidad sea producida por la procedencia tan variopinta de las imágenes que utiliza".

Siguiendo en la misma dirección, dicha universalidad también la encontramos en la disposición de sus personajes, nunca muestran sus rostros, están de espalda al observador pues se adentran en la oscuridad de la noche. En resumen, lugar y figura conforman la imagen pictórica pero el artista siente que debe unificarlos y actualizarlos con el lenguaje escrito -al igual que los

\footnotetext{
13 LA CAJA CHINA. Op.cit.

${ }^{14}$ NARANJO, José Carlos. Comunicación personal, 19 de agosto de 2015

15 SERRANO, David. "Obsesión y oscuridad en la obra de José Carlos Naranjo." Revista Estúdio, Artistas sobre outras obras. Volumen 7 , número 13, Universidad de Lisboa, 2016. p.159.
} 
artistas anteriormente analizados-: "Por ejemplo, para El camino, la chica corriendo tenía demasiado protagonismo con respecto al paisaje y con la superposición del texto, fondo y figura quedaron más nivelados". ${ }^{16}$

A Naranjo le interesa la imagen contemporánea, en concreto la estética actual callejera que ofrece el grafiti y que tanta presencia tiene en las urbes: "Esa firma de grafiti -la que aparece en El camino- no es más que una pintada que veía a diario en Nueva York, de camino a la escuela veía una puerta con esa firma. Me llamó la atención el movimiento y el desparpajo pictórico. Me gustó tanto que necesité incorporarlo a la pintura". ${ }^{17}$

Como hemos visto, los tres artistas analizados plantean tres búsquedas cibernéticas diferentes que conforman el archivo personal de imágenes que define su identidad tanto singular como colectiva. Pues el mundo globalizado ha generado una nueva conciencia del papel del individuo como parte de la sociedad y los artistas conscientes de este hecho lo objetivizan en el arte actual.

\section{CONCLUSIONES}

Una vez analizadas las estrategias creativas de nuestros protagonistas es el momento de extraer las conclusiones.

Los avances informáticos, que generan la imagen contemporánea, influyen en la identidad del artista y por tanto en su obra. Nuestros artistas son conscientes de la importancia de estos soportes virtuales, especialmente internet, pues es el espacio hacia donde deben dirigir su mirada. Como consecuencia desarrollan diferentes bancos de imágenes motivados por discursos y estrategias personales: Andrea Canepa realiza programados viajes cibernéticos, Javier Martín se aventura en una búsqueda de asociaciones absurdas y José Carlos Naranjo se empeña en unificar múltiples imágenes, creadas por él o rescatadas de internet, para construir su particular mundo.

Como hemos visto, todos ellos concilian en sus obras distintas realidades. Una cercana y privada -la historia que quieren contarnos a través de la pintura- y la otra pública y colectiva -la infinidad de realidades que llegan a conocer desde sus distintos lugares de trabajo. Ambas conforman la identidad artística de Canepa, Martín y Naranjo siendo un reflejo de la sociedad contemporánea globalizada.

\section{FUENTES REFERENCIALES.}

BOLÍVAR, Antonio. "Globalización e identidades: (des)territorialización de la cultura". Revista de Educación, núm. Extraordinario, Universidad de Granada, 2001. pp. 265-288.

BORISOVA, Anna. "Arte e identidad en la época de la globalización". Arte y políticas de identidad. Vol 6. Universidad de Murcia, 2012. pp. 275-277.

BOURRIAUD, Nicolás. Radicante. Buenos Aires: Adriana Hidalgo, 2009.

ESPINO, Luisa. Andrea Canepa. La verdad está en otra parte. Domus Artium 2002. [en línea]. 2017. [fecha de consulta: 8 Marzo 2017]. Disponible en: http://domusartium2002.com/es/EXPOSICION/andrea-canepa-2017

FOUCAULT, Michel. Esto no es una pipa. Ensayo sobre Magritte. Barcelona: Anagrama, 1993.

LA CAJA CHINA [en línea]. Nota de prensa. Sevilla: Galería de Arte La Caja China, 2015- [fecha de consulta: 12 Marzo 2017]. Disponible en: http://www.lacajachina.net/images/exposiciones/javiermartin/notaprensa.pdf

SALANOVA, Marisol y CABANES, Eurícide. "Arte versus Globalización: Revisión Filosófica de los recursos del Arte Contemporáneo frente al proceso de Globalización”. Eikasia. Revista de Filosofía, [en línea]. Año V, 31. 2010. [fecha de consulta: 6 Marzo 2017]. Disponible en: http://www.revistadefilosofia.com

SERRANO, David. "Obsesión y oscuridad en la obra de José Carlos Naranjo." Revista Estúdio, Artistas sobre outras obras. Volumen 7, número 13, Universidad de Lisboa, 2016. pp. 155-165.

\footnotetext{
${ }^{16}$ Op. Cit. p.162.

${ }^{17}$ NARANJO, José Carlos. Op. Cit.
} 